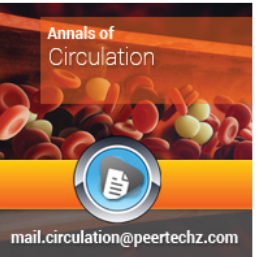

\title{
Annals of Circulation
}

Saad Rustum*, Felix Fleissner, Erik Beckmann, Fabio lus, Mathias Wilhelmi, Serghei Cebotari, Axel Haverich and Issam Ismail

Division of Cardiac, Thoracic, Transplantation and Vascular Surgery, Hannover Medical School, Hannover, Germany

Dates: Received: 20 January, 2017; Accepted: 03 February, 2017; Published: 06 February, 2017

*Corresponding author: Saad Rustum, MD, CarlNeuberg Str.1, 30625 Hannover, Germany, Tel: +495115326589, Fax: +495115325404; E-mail: rustum.saad@mh-hannover.de

Felix Fleissner, Division of Cardiac, Thoracic, Transplantation and Vascular Surgery, Hannover Medical School, Hannover, Germany,

Keywords: Coronary angiography; Transradial approach; Arterial spasm

https://www.peertechz.com

\author{
Research Article
}

\section{Is There an Upper Limit to Cardiopulmonary Bypass Times?}

\section{Abstract}

Background: There are no safe operations in cardiac surgery. Every operation can possibly go wrong. We therefore retrospectively evaluated all cardiac operations lasting more than $\mathbf{3 0 0}$ minutes of bypass time at our institution to evaluate outcome and factors relevant for perioperative mortality and morbidity.

Methods: We retrospectively included patients receiving cardiac operations or operations at the great vessels with cardiopulmonary bypass times above 300 minutes operated from 1/1/1996 until 12/1/2012 in our study. Patients receiving lung or heart or combined heart and lung transplantations were excluded from our study. 240 patients were included in our study. CPB times, clamp times and operation times were $356.53 \pm 55.06 \mathrm{~min}, 166.18 \pm 65.95 \mathrm{~min}, 500.47 \pm 96.56 \mathrm{~min}$ respectively. Euro score of patients was 14.92 \pm 15.35 (range $0.64-79.48$ ).

Results: Intraoperative and in-hospital mortality was $11.7 \%(n=28)$ and $32.9 \%(n=79)$, respectively. Overall mortality was $50.4 \%$. Complication rates were high. Stroke, postoperative dialysis, re-thoracotomy rates were $11.1 \%(n=24), 35.9 \%(n=78)$ and $30.4 \%(n=66)$, respectively. Sex, age, infectious endocarditis, need for re-thoracotomy, CABG, aortic clamp times and postoperative
dialysis predicted overall mortality in the multivariate analysis. CPB times and operation times were no
independent predictors for overall mortality in this collective.

In the patients collective excluding the intraoperative deaths, multivariate analysis revealed postoperative lactate levels, amylase levels, and intraoperative need for thrombcyte concentrates and ECMO support to be predictors of mortality. The introduction of reliable ECMO support (general availability starting in 2009) resulted in a significant reduction of intraoperative mortality and overall mortality $(p<0.001)$.

Conclusion: Very long CPB times due to intraoperative encountered complications can occur at any given Euroscore. They are associated with a high mortality and morbidity, however even bypass times of over 500 minutes can be survived. The introduction of the ECMO reduced intraoperative mortality however, had no impact on in-hospital mortality.

\section{Introduction}

Cardiac surgery is, despite all advances, still accompanied by a significant mortality and morbidity [1]. If catastrophic events in cardiac surgery happen, eg., Bleeding or impossibility of weaning of $\mathrm{CPB}$, very long bypass times can occur. Despite improvements in bypass safety, prolonged CPB times are associated with increased mortality and morbidity [2]. In the end, if there is no other choice, the cardiac surgeon has to rely on long bypass times to finish the operation. Hence we investigated the outcome of patients at our clinic who received cardiac surgery or surgery of the great vessels with a CPB time over 300 minutes. The goal was to identify prognostic markers for survival, identify perioperative morbidities and identify the upper limit to CPB times.

\section{Methods}

We retrospectively included adult patients receiving cardiac operations or operations of the great vessels with cardiopulmonary bypass times above 300 minutes operated from 1/1/1996 until 12/1/2012 in our study. Patients receiving lung or heart or combined heart and lung transplantations were excluded from our study. 240 patients were included in our study. Euroscore of patients was $14.92 \pm 15.35$ (range 0.6479.48). 95 patients (39.6\%) were re-operations. Mean age was 59.29 years \pm 13.3 (range $17-84$ years) and $69.2 \%(n=166)$ of patients were male (Table 1). Retrospective analysis of the reason for excessive $\mathrm{CPB}$ times was done by evaluation of the operation protocols. 


\section{Statistical analysis}

Primary end-points were intra-operative mortality and overall mortality. Data analysis was performed using SPSS 22.0 (IBM, NY, USA) and the Categorical and continuous variables were summarized as percentages and means \pm standard deviation (SD) or median with interquartile range (IQR), respectively. The independent-samples Student's $t$-test or the non-parametric Mann-Whitney $U$-test and the $\chi^{2}$ or Fisher's exact tests were used for group comparisons of continuous and categorical variables, respectively. Two-tailed $P$-values $\leq 0.05$ were considered significant. Multivariate analysis, using a forward stepwise logistic regression model, was performed to identify independent risk factors for intraoperative mortality and overall mortality. Model calibration was evaluated using the Hosmer-Lemeshow (H-L) goodness-of-fit test. A Cox regression analysis was performed to identify independent risk factors for mortality conditioned to hospital discharge. Results are reported as odds ratios (ORs) with a 95\% confidence interval (CI) and corresponding $p$-value.

\section{Results}

CPB times, clamp times and operation times were $356.53 \pm$ $55.06 \mathrm{~min}, 166.18 \pm 65.95 \mathrm{~min}, 500.47 \pm 96.56 \mathrm{~min}$ respectively (Table 2). The performed surgery and indication for surgery was heterogenous (Tables 1-3). Indication for surgery was endocardits, acute aortic and chronic aortic dissection, chronic pulmonary embolism, and myocardial tumors in $10.9 \%(n=26)$, $25.4 \%(n=61), 3.8 \%(n=9)$ and $1.3 \%(n=3)$, respectively.

However, the reason remained unclear in some cases (21.7\%, $\mathrm{n}=52)$. Main indication for long CPB times was difficult surgery, bleeding, difficulties of weaning of the $\mathrm{CPB}$, iatrogenic dissections and other iatrogenic complications (AV dislocation, rupture of $\mathrm{AV}$ integrity and alike) in $17.5 \%, 29.6 \%, 36.7 \%$, $6.3 \%$ respectively.

Intraoperative and intrahospital mortality was $11.7 \%(\mathrm{n}=28)$ and $32.9 \%(\mathrm{n}=79)$, respectively. Overall mortality was $50.4 \%$ $(n=121)$. Intraoperative blood products were administered in every patient with red packed blood cells (RBC) $13.77 \pm$ 12.63 units, Fresh frozen plasma (FFP) $10.21 \pm 8.38$ units and thrombocyte concentrates (TC) $3.96 \pm 3.37$ units. Overall blood products were RBC, FFP and TC $24.78 \pm 21.57$ units, $20.78 \pm$ 18.57 units and $10.03 \pm 18.06$ units, respectively (Table 4 ). 36 patients $(15 \%)$ received extracorporal membrane oxygenatory support (ECMO) and 46 patients (19.2\%) received intraaortic balloon pump (IABP). Almost all patients represented elevated liver and kidney retention parameters. Complication rates were high. Stroke, postoperative dialysis and re-thoracotomy rates were $11.1 \%(n=24), 35.9 \%(n=78)$ and $30.4 \%(n=66)$, respectively. Postoperative ventilation time was 140.14 \pm 269.81 hours. ICU stay was $11.32 \pm 16.44$ days. Cause of death were heart failure, right heart failure, bleeding, multi-organ failure and cerebral cause in $17.9 \%(n=43), 1.3 \%(n=3), 3.3$ $(n=8), 19.6 \%(n=47) 1.3 \%(n=3)$, respectively.

Sex, age, infectious endocarditis, need for re-thoracotomy, CABG, aortic clamp times and postoperative dialysis predicted overall mortality in the multivariate analysis. CPB times and
Table 1: Patient's characteristics. Patients characteristics. Continuous variables are presented with the standard deviation; categoric variables are presented as number (\%), СTEPH: chronic thromboembolic pulmonary hypertension.

\begin{tabular}{|c|c|} 
Euroscore & $14.92 \pm 15.35$ \\
\hline Age (years) & $59.29 \pm 13.3$ \\
\hline Sex, male $(\mathrm{n})$ & $69.2 \%(166)$ \\
\hline Re-operation \% $(\mathrm{n})$ & $39.6 \%(95)$ \\
\hline Endocarditis \% $(\mathrm{n})$ & $10.9(26)$ \\
\hline Acute aortic dissection & $25.4(61)$ \\
\hline CTEPH & $3.8(9)$ \\
\hline Acute myocardial infarction & $3.8(9)$ \\
\hline Tumor & $1.3(3)$
\end{tabular}

Table 2: Operational details and early outcome. Operational details and early outcome. Continuous variables are presented with the standard deviation or range; categoric variables are presented as number. RBC: Red packed blood cells, FFP: Fresh frozen plasma, TC: thrombocyte concentrates, ECMO: extra-corporeal membrane oxygenation, IABP: intra-aortic balloon pump, ICU Intensive care unit.

\begin{tabular}{|c|c|}
\hline CPB times (min) & $356.53 \pm 55.06$ \\
\hline Operation times (min) & $500.47 \pm 96.56$ \\
\hline Aortic clamp times (min) & $166.18 \pm 65.95$ \\
\hline Euroscore & $14.92 \pm 15.35$ \\
\hline Death intraoperative \% (n) & $11.7(28)$ \\
\hline Death intra-hospital \% (n) & $32.9(79)$ \\
\hline Cumulative mortality & $50.4(121)$ \\
\hline \multicolumn{2}{|l|}{ Intraoperativly: } \\
\hline $\mathrm{RBC}$ & $13.77 \pm 12.63$ \\
\hline FFP & $10.21 \pm 8.38$ \\
\hline $\mathrm{TC}$ & $3.96 \pm 3.37$ (range: $0-30$ ) \\
\hline \multicolumn{2}{|l|}{ Overall: } \\
\hline $\mathrm{RBC}$ & $24.78 \pm 21.57$ \\
\hline FFP & $20.78 \pm 18.57$ \\
\hline $\mathrm{TC}$ & $10.03 \pm 18.06$ \\
\hline ECMO support \% (n) & $15.0(36)$ \\
\hline IABP support \% (n) & $19.2(46)$ \\
\hline Ventilation times (hours) & $140.14 \pm 269.81$ \\
\hline ICU stay (days & $11.32 \pm 16.44$ \\
\hline Hospital stay & $22.09 \pm 20.97$ (range: 1-173) \\
\hline Stroke \% (n) & $11.1(24)$ \\
\hline Postoperative dialysis \% (n) & $35.9(78)$ \\
\hline Re-Thoracotomy \% (n) & $30.4(66)$ \\
\hline
\end{tabular}

operation times were no independent predictors for overall mortality in this collective (Table 5).

In the patients collective excluding the intraoperative deaths, multivariate analysis revealed postoperative lactate levels, amylase levels, intraoperative need for thrombcyte concentrates and ECMO support to be predictors of mortality (Table 6).

Intraoperative death was predicted by CABG, absence of reliable ECMO support (before 2009) and intraoperative FFP usage. 
Establishment of reliable ECMO support may result in reduced intraoperative deaths. To further evaluate the impact of ECMO support on our patients collective, two groups were formed, Group 1 before establishment of a 24/7 availability of ECMO and Group 2 after the general availability of ECMO support, beginning after 2009. Between the years 1996 and 12/2008, 9 (14\%) patients received ECMO support perioperativly, whereas after general availability after 2009, 22 patients $(26.2 \%)(\mathrm{p}<0.001)$ received ECMO support. The two groups were comparable in indications for surgery with a similar Euroscore (Table 7).

Intraoperative death was significantly reduced in group 2

Table 3: Operational procedures. Performed operational procedures, simplified to give an overview about the performed heterogeneous surgery. Categoric variables are presented as number, CABG: Coronay artery bypass grafting, FET: Frozen Elephant trunk technique, ET: "Classical" Elephant trunk technique, TAA: Throacoabdominal aortic aneurysm, PTE: Pulmonary Thromboendarterectomy, VSD: ventricular septum defect.

\section{single valve repair/replacement}

\begin{tabular}{c|c} 
w/o CABG & 15 \\
w CABG & 14
\end{tabular}

double valve repair/replacement

\begin{tabular}{c|c} 
w/o CABG & 15 \\
w CABG & 12
\end{tabular}

tripple valve repair/replacement

\begin{tabular}{c|c} 
w/o CABG & 2 \\
w CABG & 3
\end{tabular}

Aortic surgery

Ascending aortic replacment

W/o CABG

5

w CABG

Ascending aortic replacment+ Aortic

valve repair/replacement

W/o CABG

w CABG

Ascending aortic/prox. arch replacment

W/o CABG

w CABG

Ascending aortic/prox. arch replacment

+ Aortic valve repair/replacement

w/o CABG

29

w CABG

Ascending aortic/complete arch

replacment (FET/ET)

\begin{tabular}{c|c} 
W/o CABG & 15 \\
\hline W CABG & 9
\end{tabular}

Ascending aortic/complete arch replacment (FET/ET) + Aortic valve repair/ replacement

\begin{tabular}{|c|c|}
\hline w/o CABG & 1 \\
\hline w CABG & 5 \\
\hline CABG & 1 \\
\hline TAA & 1 \\
\hline PTE & 9 \\
\hline Tumour & 3 \\
\hline ROSS & 5 \\
\hline VSD & 1 \\
\hline
\end{tabular}

Table 4: Univariate and multivariate analysis of risk factors for intraoperative death RBC: Red packed blood cells, FFP: Fresh frozen plasma, ECMO: extra-corporeal membrane oxygenation, IABP: intra-aortic balloon pump, RBC: Red packed blood cells, FFP: Fresh frozen plasma, TC: thrombocyte concentrates.

\begin{tabular}{|c|c|c|c|c|}
\hline \multirow{2}{*}{ Variable } & \multirow{2}{*}{$\begin{array}{c}\text { Univariate } \\
\text { P }\end{array}$} & \multicolumn{3}{|c|}{ Multivariate } \\
\hline & & $\mathbf{P}$ & $\operatorname{Exp}(B)$ & $\begin{array}{c}\text { 95\% confindence } \\
\text { interval }\end{array}$ \\
\hline $\begin{array}{l}\text { Acute myocardial } \\
\text { infarction }\end{array}$ & 0.016 & & & \\
\hline Bental & 0.102 & & & \\
\hline CABG & 0.000 & 0.001 & 4.556 & $0.036-0.75$ \\
\hline DOR & 0.08 & & & \\
\hline ECMO availability & 0.00 & 0.02 & 0.164 & $0.036-0.75$ \\
\hline ECMO yes/no & 0.037 & & & \\
\hline IABP yes/no & 0.015 & & & \\
\hline Age & 0.126 & & & \\
\hline Operation time & 0.053 & & & \\
\hline CPB time & 0.363 & & & \\
\hline Aortic clamp time & 0.003 & & & \\
\hline $\mathrm{RBC}$ & 0.00 & & & \\
\hline FFP & 0.000 & 0.017 & 0.871 & $0.777-0.976$ \\
\hline $\mathrm{TC}$ & 0.318 & & & \\
\hline Euroscore & 0.242 & & & \\
\hline
\end{tabular}

Table 5: Univariate and multivariate analysis of risk factors for overall death. ECMO: extra-corporeal membrane oxygenation, CPB: cardiopulmonary bypass, RBC: Red packed blood cells, FFP: Fresh frozen plasma, TC: thrombocyte concentrates.

\begin{tabular}{|c|c|c|c|c|}
\hline Variable & Univariate & \multicolumn{3}{|c|}{ Multivariate } \\
\hline sex & P & P & Exp (B) & 95\% confindence interval \\
\hline endocarditis & 0.007 & 0.015 & 0.427 & $0.215-0.848$ \\
\hline triple valve surgery & 0.010 & 0.001 & 6.350 & $2.093-19.266$ \\
\hline ascending aorta & 0.092 & & & \\
\hline CABG & 0.018 & 0.036 & 2.029 & $1.047-3.932$ \\
\hline re-thoracotomy & 0.010 & & & \\
\hline dialysis & 0.000 & 0.00 & 5.381 & $2.690-10.765$ \\
\hline ECMO yes/no & 0.001 & & & \\
\hline age & 0.001 & 0.032 & 1.029 & $1.002-1.056$ \\
\hline Operation time & 0.082 & & & \\
\hline CPB time & 0.030 & & & \\
\hline Aortic clamp time & 0.040 & 0.019 & 0.994 & $0.990-0.999$ \\
\hline RBC & 0.156 & & & \\
\hline FFP & 0.687 & & & \\
\hline TC & 0.030 & 0.03 & 1.1146 & \\
\hline Euroscore & 0.000 & & & \\
\hline
\end{tabular}

(Group 1 17.9\% vs. Group 2 2.4\%, p<0.001). However cumulative in-hospital mortality remained the same (Group $149.4 \%$ vs. Group 2 52.4\%, p=0.686).

\section{Discussion}

Prolonged CPB times are associated with an increase in 
mortality and morbidity [2]. Even in isolated aortic valve surgery and CPB times above 90 minutes excluded, CPB time remains a significant factor for blood loss, ICU and hospital length of stay as well as in-hospital mortality [3]. The patient's collective in this study was predominantly sick, with high rates of acute aortic dissections, endocarditis and re-operations. These patients often require long CPB times since intraoperative problems are often encountered. However, even patients with a predicted low Euroscore sometimes require long $\mathrm{CPB}$ times due to unexpected intraoperative complications. At CPB times above 300 minutes, the $\mathrm{CPB}$ time does not longer predict the overall outcome. The longest $\mathrm{CPB}$ time survived in our cohort was above 500 minutes. This indicates that CPB time should not hinder the cardiac surgeon to continue surgery, since these patients requiring such excessive $\mathrm{CPB}$ times still have a chance of survival. The introduction of the ECMO and general availability lead to a significant reduction in intraoperative mortality, however, it had no effect on overall in-hospital mortality. Venous arterial ECMO therapy enables support of unstable patients and critically ill patients in cardiogenic shock and allows temporary hemodynamic stabilization with improvement of end-organ function [4]. Most patients after long CPB times require hemodynamic stabilization as well as respiratory support due to oxygenatory failure; therefore a venous/venous ECMO is not the preferred option in these patients $[5,6]$.

Table 6: Univariate and multivariate analysis of risk factors for overall death excluding intraoperative death. RBC: Red packed blood cells, FFP: Fresh frozen plasma, ECMO: extra-corporeal membrane oxygenation, IABP: intra-aortic balloon pump, RBC: Red packed blood cells, FFP: Fresh frozen plasma, TC: thrombocyte concentrates, CPB: cardiopulmonary bypass.

\begin{tabular}{|c|c|c|c|c|}
\hline \multirow[t]{2}{*}{ Variable } & Univariate & \multicolumn{3}{|c|}{ Multivariate } \\
\hline & $P$ & $P$ & $\operatorname{Exp}(B)$ & $\begin{array}{c}95 \% \text { confindence } \\
\text { interval }\end{array}$ \\
\hline Sex & 0.005 & & & \\
\hline Endocarditis & 0.010 & & & \\
\hline Rethoracotomy & 0.000 & & & \\
\hline Dialysis & 0.000 & & & \\
\hline ECMO yes/no & 0.000 & 0.002 & 11.149 & $2.399-51.818$ \\
\hline ECMO availability & 0.086 & & & \\
\hline age & 0.004 & & & \\
\hline Operation time & 0.008 & & & \\
\hline CPB time & 0.049 & & & \\
\hline RBC & 0.019 & & & \\
\hline \multicolumn{5}{|l|}{ FFP } \\
\hline $\mathrm{TC}$ & 0.022 & 0.010 & 1.662 & $1.127-2.425$ \\
\hline Euroscore & 0.000 & & & \\
\hline CK-MB & 0.001 & & & \\
\hline GOT & 0.005 & & & \\
\hline GPT & 0.037 & & & \\
\hline LDH & 0.011 & & & \\
\hline Lactat & 0.015 & 0.032 & 1.123 & $1.010-1.248$ \\
\hline Amylase & 0.000 & 0.036 & 1.003 & 1.006 \\
\hline Lipase & 0.003 & & & \\
\hline CRP & 0.014 & & & \\
\hline
\end{tabular}

Table 7: Subgroup analysis for Patients operated with ECMO standby vs. no general availability of ECMO support. Subgroup analysis for Patients operated with ECMO standby vs. no general availability of ECMO support. Continuous variables are presented with the standard deviation; categoric variables are presented as number (\%). RBC: Red packed blood cells, FFP: Fresh frozen plasma, TC: thrombocyte concentrates, ECMO: extra-corporeal membrane oxygenation, IABP: intra-aortic balloon pump, ICU: Intensive care unit.

\section{\begin{tabular}{|l|l|l|l|}
\hline Group 1: Before 2009 & Group 2: After 2009 & P
\end{tabular}}

Pre-operative data sex

Age (years)

Re-operation \% (n)

Endocarditis \% (n)

Acute aortic dissection

CTEPH

Acute myocardial

infarction

Tumor

Euroscore

Intraoperative data

CPB times (min)

Operation times ( $\mathrm{min})$

Aortic clamp times (min)

ECMO \% (n)

IABP \% (n)

Intraoperative

$\mathrm{RBC}$

FFP

TC

Overall:

RBC

FFP

TC

Outcome

Death in-hospital \% (n)

Cumulative mortality

Ventilation times (hours)

ICU stay (days)

Hospital stay
Death intraoperative \% (n)
$69.9(106)$

$58.41 \pm 13.37$

39.1 (61)

9 (14)

$26.3(41)$

$3.8(6)$

$5.8(9)$

$1.3(2)$

16.26(69-79.48)

$358.18 \pm 56.35$

$497.13 \pm 99.58$

$160.1 \pm 66.121$

9 (14)

$23.1(36)$

\section{$14.75 \pm 14.089$ \\ $10.7 \pm 8.51$ \\ $4.2(0-30)$}

$24.4 \pm 21.74$

$21.15 \pm 18.97$

$10.72 \pm 21.49$

$17.9(28)$

31.4 (49)

49.4 (77)

$78.62 \pm 250.38$

$9.61 \pm 17.93$

$19.87 \pm 22.08$

\begin{tabular}{c|c}
$67.9(57)$ & $\mathrm{p}=0.771$ \\
$60.32 \pm 13.17$ & $\mathrm{p}=0.381$ \\
$40.5(34)$ & $\mathrm{p}=0.89$ \\
$14.3(12)$ & $\mathrm{p}=0.276$ \\
$23.8(20)$ & $\mathrm{p}=0.757$ \\
$3.6(3)$ & $\mathrm{p}=0.29$ \\
$1.2(1)$ & $\mathrm{p}=1$ \\
$1.2(1)$ & $\mathrm{p}=1$
\end{tabular}

$12.48(0.64-76.73) \quad p=0.145$

$353.46+52.774$

$506.67 \pm 90.93$

$176.95 \pm 64.62$

26.2 (22)

$11.9(10)$

$p=0.528$

$p=0.557$

$p=0.059$

$p<0.001$

$p=0.04$

$9.9 \pm 7.99$

$3.52(0-10)$

$p=0.157$

$\mathrm{p}=0.487$

$p=0.347$

$25.49 \pm 21.36$

$\mathrm{p}=0.417$

$20.07 \pm 17.886$

$\mathrm{p}=0.428$

$8.72 \pm 8.39$

$\mathrm{p}=0.417$

$2.4(2)$

$<0.001$

$42(50)$

$p=0.005$

$52.4(44)$

$p=0.686$

$205.23 \pm 248.49 \quad p=0.001$

$10.88 \pm 17.63 \quad p=0.555$

$20.25 \pm 17.64 \quad p=0.348$
As expected, the patients with such complicated operations and therefore long CPB times are prone for complications $[7,8]$. The re-thoracotomy rate was above $30 \%$ (excluding patients with intraoperative death). Kidney function was affected in almost all patients with a high rate of requirement for dialysis postoperatively [9]. Euroscore failed to predict mortality in this group [6]. Nonetheless, the mortality in this patient collective well exceeded the predicted Euroscore due to a negative selection of only those patients with long CPB times. This might in fact be due to rather unexpected complications encountered such as the rare entity of iatrogenic aortic dissections and alike. CABG was an independent risk factor for intraoperative and overall death. This is most likely due to rescue attempts during cardiac 
surgery, performing CABG as a bailout if the weaning from CBP is unsuccessful and myocardial ischemia has to be expected.

Re-sternotomy is usually due to technical issues regarding the operation or coagulopathy. In our study, longer CPB times were associated with an increased need for blood transfusions. This underlines the hypothesis, that the longer CPB times, the longer contact between foreign surfaces of the extracorporeal circuit resulting in increased severity of systemic inflammatory response. However, CRP as a marker for systemic inflammation was not increased with longer CPB times [10].

Longer cross clamp times are associated with a great risk of myocardial ischemia [2]. However, in our long CPB times, we were not able to identify $\mathrm{CPB}$ or cross clamp time as a significant factor determining creatinine kinase muscle-brain isoenzyme (CK-MB), creatinine kinase (CK) or myoglobine release a surrogate marker for myocardial ischemia $(p=0.573$ CK-MB, $\mathrm{p}=0.112 \mathrm{CK}, \mathrm{p}=0.626$ myoglobine). Perioperative myocardial infarction remains frequent in cardiac surgery with an incidence from $8 \%$ to $35 \%$ [11]. This wide variation is due to criteria and tests employed by different investigators institutions. However, the pathogene1perioperative myocardial infarction is not well understood. Inadequate myocardial protection during cardiopulmonary bypass (CPB), perioperative vasospasm, and atheroembolism are some of the current theories $[12,13]$. Increased duration of CPB and aortic occlusion are associated with a higher incidence of myocardial infarction [2].

As expected there were several early and independent markers to predict postoperative death. These were all markers of kidney and liver function such as lactate levels, amylase. Therefore, one can conclude that the damage to the organs is done already intraoperativly affecting the overall survival in our group.

\section{Conclusion}

Every cardiac surgery can possibly go wrong, even if the Euroscore predicts a low morbidity and mortality. If intraoperative encountered problems occur and long CPB times are needed to handle them, even very long CPB times can be survived, however the mortality and morbidity is high. The introduction of ECMO support had a great impact on intraoperative mortality, however the overall mortality seems to be unaffected by ECMO support in this collective.

\section{Limitations}

Limitations to this study is the retrospective data evaluation, the lack of a control group and the long time course over which operational techniques and CBP support have changed significantly. However, a long term follow up would be possibly biased by the very heterogenous patient collective. We assume that within a longer time frame, the underlying disease of the patients would make a comparison of mid to long term survival very difficult.

\section{References}

1. Nashef SA, Roques F, Sharples LD, Nilsson J, Smith C, et al. (2012) EuroSCORE II Eur J Cardiothorac Surg 41: 734-744. Link: https://goo.gl/0Jq4OW

2. Salis S, Mazzanti VV, Merli G, Salvi L, Tedesco C, et al. (2008) Cardiopulmonary bypass duration is an independent predictor of morbidity and mortality after cardiac surgery $\mathrm{J}$ Cardiothorac Vasc Anesth 22: 814-822. Link: https://goo.gl/v60Zku

3. Chalmers J, Pullan M, Mediratta N, Poullis M (2014) A need for speed? Bypass time and outcomes after isolated aortic valve replacement surgery. Interact Cardiovasc Thorac Surg 19: 21-6. 3. Link: https://goo.gl/2RWgjj.

4. Guzzetta NA, Allen NN, Wilson EC, Foster GS, Ehrlich AC, et al (2015) Excessive postoperative bleeding and outcomes in neonates undergoing cardiopulmonary bypass. Anesth Analg. 120: 405-410. Link: https://goo.gl/htl40P

5. Banfi C, Pozzi M, Brunner ME, Rigamonti F, Murith N, et al. (2016) Veno-arterial extracorporeal membrane oxygenation: an overview of different cannulation techniques. J Thorac Dis. 8: E875-E885. Link: https://goo.gl/gRjdCD

6. Nagpal AD, Singal RK, Arora RC, Lamarche Y. (2017) Temporary Mechanica Circulatory Support in Cardiac Critical Care: A State of the Art Review and Algorithm for Device Selection. Can J Cardiol 33: 110-118. Link: https://goo.gl/6240K1

7. Brown WR, Moody DM, Challa VR, Stump DA, Hammon JW (2000) Longer duration of cardiopulmonary bypass is associated with greater numbers of cerebral microemboli. Stroke 31: 707-713. Link: https://goo.gl/voOZiJ

8. Liakopoulos OJ, Kuhn EW, Choi YH, Chang W, Wittwer T, et al. (2010) Myocardial protection in cardiac surgery patients requiring prolonged aortic cross-clamp times: a single-center evaluation of clinical outcomes comparing two blood cardioplegic strategies J Cardiovasc Surg (Torino) 51: 895-905. Link: https://goo.gl/xCBc4t

9. Pickering JW, James MT, Palmer SC. (2015) Acute Kidney Injury and Prognosis After Cardiopulmonary Bypass: A Meta-analysis of Cohort Studies. Am J Kidney Dis 65: 283-293. Link: https://goo.gl/GL9Wdu

10. Garg AX, Devereaux PJ, Yusuf S, Cuerden MS, Parikh CR, et al. (2014) Kidney function after off-pump or on-pump coronary artery bypass graft surgery: a randomized clinical trial.; JAMA. 311: 2191-2198.Link: https://goo.gl/htl40P

11. Nashef SA, Roques F, Michel P, Cortina J, Faichney A, et al. (2000) Coronary surgery in Europe: comparison of the national subsets of the European system for cardiac operative risk evaluation database. Eur $\mathrm{J}$ Cardiothorac Surg. 17: 396-399. Link: https://goo.gl/BXNLHx

12. Jain $U$ (1992) Myocardial Infarction during coronary artery bypass surgery. J Cardiothorac Vasc Anes 6: 612-623. Link: https://goo.gl/9fOVVZ

13. Carrier M, Pellerin M, Perrault LP, Solymoss BC, Pelletier LC (2000) Troponin levels in patients with myocardial infarction after coronary bypass grafting Ann Thorac Surg 69: 435-440. Link: https://goo.gl/rT4qSe

14. Sommer W, Marsch G, Kaufeld T, Röntgen P, Beutel G, et al. (2015) Cardiac awake extracorporeal life support-bridge to decision? 39:400-408. Link: https://goo.gl/oa9w8P

15. Kleinbongard $P$, Neuhäuser $M$, Thielmann $M$, Kottenberg $E$, Peters J, et al. (2016) Confounders of Cardioprotection by Remote Ischemic Preconditioning in Patients undergoing Coronary Artery Bypass Grafting. Cardiology 133(2):128-33. Link: https://goo.gl/IJ0caY

Copyright: (c) 2017 Rustum S, et al. This is an open-access article distributed under the terms of the Creative Commons Attribution License, which permits unrestricted use, distribution, and reproduction in any medium, provided the original author and source are credited. 